\title{
INCREASED NITRIC OXIDE SYNTHASE ACTIVITY AFTER CANINE CARDIOPULMONARY BYPASS IS SUPPRESSED BY S-NITROSOGLUTATHIONE
}

Irvin Mayers, $\mathrm{MD}^{\mathrm{a}}$

Eduardo Salas, MD, $\mathrm{PhD}^{\mathrm{b}}$

Thomas Hurst, MVSc ${ }^{c}$

David Johnson, MD ${ }^{\mathrm{d}}$

Marek W. Radomski, MD, $\mathrm{PhD}^{\mathrm{b}}$
Objectives: Hemodynamic instability and generalized organ dysfunction are common after cardiopulmonary bypass in human beings. Previous studies have suggested that alterations of nitric oxide metabolism may be associated with this impaired function. Using a canine model we tested whether nitric oxide synthase activity is increased after cardiopulmonary bypass. We also tested whether administration of a nitric oxide donor can influence nitric oxide synthase activity after cardiopulmonary bypass. Methods: After induction of anesthesia, dogs were randomized to receive cardiopulmonary bypass $(n=12)$ or to serve as controls $(n=12)$. They were further randomized to receive a continuous infusion of a nitric oxide donor, $S$-nitrosoglutathione, or an equivalent volume of placebo. Cardiopulmonary bypass was maintained for 90 minutes, and then 4 hours later dogs were put to death. Cardiac and coronary artery sections were frozen in liquid nitrogen immediately after death for later determination of nitric oxide synthase activity using a citrulline assay. Results: After cardiopulmonary bypass, 4 of 6 placebotreated but only 2 of $6 \mathrm{~S}$-nitrosoglutathione-treated animals required phenylephrine infusion $(3.1 \pm 3.1 \mu \mathrm{g} / \mathrm{min}$ and $0.2 \pm 0.4 \mu \mathrm{g} / \mathrm{min}$, respectively, $P=.05$ ) to maintain a predetermined blood pressure. Furthermore, after cardiopulmonary bypass, $\mathrm{Ca}^{2+}$-dependent nitric oxide synthase activity in the left ventricle, atrium, and coronary artery did not increase compared with activity in the control animals, but $\mathrm{Ca}^{2+}$-independent nitric oxide synthase activity did increase $(P=\mathbf{. 0 0 5})$ : left ventricle $(+\mathbf{2 8 . 0 \%} \pm \mathbf{9 . 0} \%)$, atrium $(+\mathbf{4 5 . 0 \%} \pm \mathbf{1 2 . 0 \%})$ and coronary artery $(+\mathbf{1 7 . 0 \%} \pm \mathbf{1 2 . 0 \%})$. Conclusions: We have found that (1) cardiopulmonary bypass results in increased activity of $\mathrm{Ca}^{2+}$-independent nitric oxide synthase, (2) S-nitrosoglutathione can prevent the increase of $\mathrm{Ca}^{2+}$-independent nitric oxide synthase after cardiopulmonary bypass, and (3) $\mathrm{Ca}^{2+}$-independent nitric oxide synthase may contribute to hemodynamic dysfunction after cardiopulmonary bypass. (J Thorac Cardiovasc Surg 1999;117:1009-16)
$\mathrm{N}_{\mathrm{sit}}$ itric oxide (NO) is synthesized by the nitric oxide synthase (NOS) family of isoenzymes, which converts L-arginine to $\mathrm{NO}$ and L-citrulline. ${ }^{1}$ The roles of constitutive NOS and inducible NOS (iNOS) in modulating cardiac contractility have been recently reviewed. $^{2}$ Either deficient $^{3}$ or excessive ${ }^{4}$ generation of NO appears to be detrimental to heart function. Thus

From Departments of Medicine ${ }^{\mathrm{a}}$ and Pharmacology, ${ }^{\mathrm{b}}$ University of Alberta, Edmonton, and the Departments of Medicine ${ }^{c}$ and Anaesthesia, ${ }^{\mathrm{d}}$ University of Saskatchewan, Saskatoon, Saskatchewan, Canada.

This work was supported by a grant from the Saskatchewan Heart and Stroke Foundation.

Received for publication June 2, 1998; revisions requested Aug 10, there appears to be a delicate balance of NO bioactivity necessary for optimal cardiac performance after a cardiac injury.

Cardiopulmonary bypass (CPB) can be considered as a form of inflammatory injury ${ }^{5}$ whose precise timing is controlled and is associated with the release of proinflammatory cytokines. ${ }^{6}$ Pro-inflammatory cytokines

1998; revisions received Jan 21, 1999; accepted for publication Jan 21, 1999.

Address for reprints: Irvin Mayers, MD, Department of Medicine, Walter C. Mackenzie Health Sciences Centre, Edmonton, Alberta, Canada.

Copyright (C) 1999 by Mosby, Inc.

$0022-5223 / 99 \$ 8.00+0 \quad \mathbf{1 2 / 1 / 9 7 3 7 8}$ 


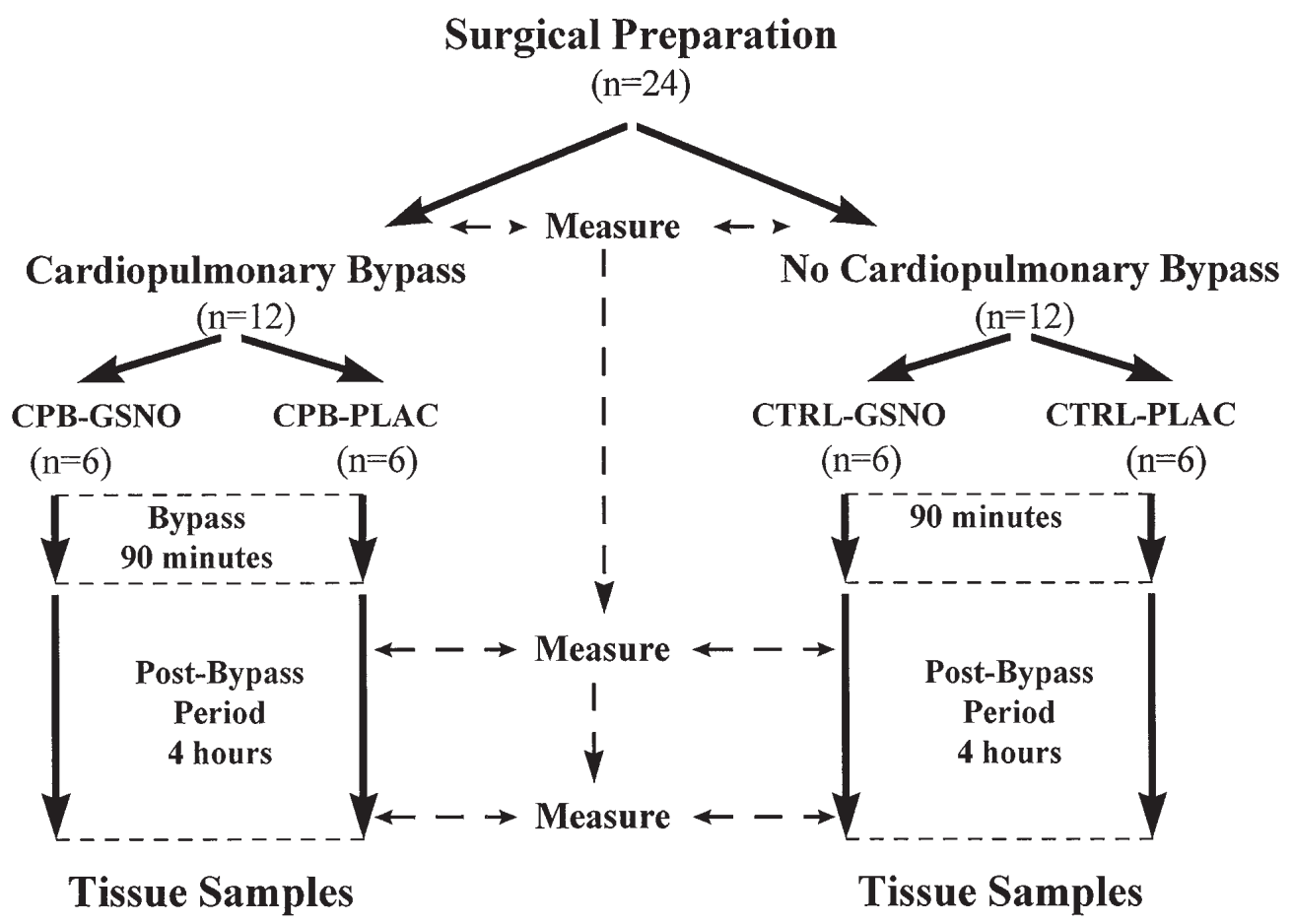

Fig 1. Protocol followed by the 4 groups of dogs. Animals were randomized to receive cardiopulmonary bypass (CPB-PLAC or CPB-GSNO) or to serve as control (CTRL-PLAC or CTRL-GSNO).

in turn may induce iNOS and thereby impair cardiac muscle performance. ${ }^{7}$ Although myocardial levels of $\mathrm{NO}$ are increased after $\mathrm{CPB},{ }^{8}$ this increase has not been previously ascribed to the action of iNOS. Therefore we have tested whether the activity of iNOS is increased after $\mathrm{CPB}$ and have further hypothesized that administration of an NO donor might down-regulate the resultant increased activity of iNOS. ${ }^{9}, 10$ We have tested the effects of the NO donor S-nitrosoglutathione (GSNO) because it can inhibit blood cell activation at doses lower than those required to elicit vasodilatation $^{11}$ and protect against an oxidative injury. ${ }^{12}$ Our study shows that CPB leads to an increased activity of iNOS and that this effect is inhibited by GSNO.

\section{Methods}

Animal preparation. These studies were carried out with the approval of the University of Saskatchewan Animal Care Committee. They are in compliance with the "Principles of Laboratory Animal Care" formulated by the National Society for Medical Research and the "Guide for the Care and Use of Laboratory Animals" published by The National Institutes of Health. Dogs were anesthetized with pentobarbital (15 $\mathrm{mg} / \mathrm{kg}$ ), intubated, and their lungs mechanically ventilated (Respiratory Pump, model 607, Harvard Apparatus Co, Dover, Mass). Anesthesia was maintained with a constant infusion of pentobarbital ( $1.0 \mathrm{mg} / \mathrm{kg}$ per hour), morphine $(0.1$ $\mathrm{mg} / \mathrm{kg}$ per hour), and vecuronium $(0.1 \mathrm{mg} / \mathrm{kg}$ per hour). A thermistor-tipped pulmonary artery catheter introduced through the right external jugular vein was used to measure mean pulmonary artery pressure, pulmonary capillary wedge pressure, mean right atrial pressure, and cardiac output. A catheter inserted through the femoral artery was used to measure mean systemic artery pressure and obtain blood samples for arterial blood gas analysis. Vascular pressures were measured with disposal transducers (Cobe Laboratories, Inc, Lakewood, Colo) and continuously displayed (Space Labs, model 510, Squibb, Hollsboro, Ore).

To obtain wide surgical access, we performed bilateral thoracotomies through the fifth intercostal spaces. Heparin was administered (5000 U intravenously followed by 1000 units/h intravenously), and via the left atrial appendage a noncompliant catheter $(8 \mathrm{~F})$ was positioned in the left atrium just above the mitral valve. This catheter was used to measure left atrial pressure, sample left atrial blood, and decompress the left ventricle during CPB. A balloon angioplasty catheter $(6 \mathrm{~F})$ was positioned just proximal to the aortic valve via the right internal carotid artery and its position manually confirmed. When the angioplasty catheter was inflated to its maximal volume $(10 \mathrm{~mL})$ within the aorta, it produced the equivalent of externally crossclamping the aorta. Before the start of CPB, a cannula was inserted into the right atrium to complete the bypass circuit. Arterial blood from the oxy- 
genator was returned to the animals through the femoral artery catheter.

CPB was initiated with a membrane oxygenator (Capiox Hollow Fiber Oxygenator, Terumo Corporation, Tokyo, Japan) and a blood pump (Sarns model 5000 Console, Sarns $/ 3 \mathrm{M}$, Ann Arbor, Mich) at a flow rate of $100 \mathrm{~mL} / \mathrm{kg}$. Cold $\left(7^{\circ} \mathrm{C}-8^{\circ} \mathrm{C}\right)$ cardioplegic solution was delivered antegradely through the distal port of the aortic angioplasty catheter and consisted of a mixture of saline solution/potassium and blood in a 1:2 ratio. Five minutes after the initiation of $\mathrm{CPB}$, the aorta was occluded by inflation of the angioplasty balloon. Blood cardioplegia (BCD4 Sharely, Anaheim, Calif) was then commenced, initially at a $\mathrm{KCl}$ concentration $30 \mathrm{mEq} / \mathrm{L}$ and subsequently at a concentration to $10 \mathrm{mEq} / \mathrm{L}$. Cardioplegic solution with continuous surface cooling was administered to eliminate electrical activity. The animals were systemically cooled to $24^{\circ} \mathrm{C}$ over 10 minutes, and the aortic balloon inflation was maintained for a further $50 \mathrm{~min}$ utes. Before the aortic balloon was deflated, $150 \mathrm{~mL}$ of warm cardioplegic solution without $\mathrm{KCl}$ supplementation was administered. In the animals receiving GSNO, an additional dose of GSNO $(1.5 \mu \mathrm{g} / \mathrm{kg})$ was administered with the initial and final cardioplegic solution. After deflation of the aortic balloon, mechanical ventilation, which had been stopped during $\mathrm{CPB}$, was resumed and the animals were warmed to $37^{\circ} \mathrm{C}$ over the subsequent 30 minutes. In this manner, total $\mathrm{CPB}$ lasted for 90 minutes. Any blood collected within the thoracic cavity was transfused into the CPB circuit. The dogs were observed for a further 4 hours after cessation of CPB. During this period systemic and right atrial pressures were maintained at more than 60 and between 5 and $15 \mathrm{~mm} \mathrm{Hg}$, respectively. If systemic arterial pressure remained below $60 \mathrm{~mm}$ $\mathrm{Hg}$ despite radial artery pressure being raised to $15 \mathrm{~mm} \mathrm{Hg}$ by a volume infusion, an infusion of phenylephrine was titrated for a systemic arterial pressure of more than $60 \mathrm{~mm} \mathrm{Hg}$.

Experimental groups. Fig 1 outlines our experimental protocol. A total of 24 mongrel dogs $(20-25 \mathrm{~kg})$ were studied. Twelve dogs were randomized to receive CPB and 12 were randomized to serve as controls. Of the animals randomized to $\mathrm{CPB}, 6$ dogs were further randomized to receive a continuous infusion of GSNO (CPB-GSNO) and 6 dogs received a similar volume of placebo (CPB-PLAC). At higher doses GSNO also exerts a vasodilator effect ${ }^{13}$; therefore, to deliver a near maximal nonvasodilator dose of GSNO, we found the dose of GSNO that decreased systemic arterial pressure by $10 \%$ below baseline values in each animal. This dose of GSNO was then maintained at a constant infusion rate starting just before the thoracotomies were performed and ending 30 minutes after the cessation of CPB. The GSNO infusion was delivered through the proximal port of the pulmonary artery catheter.

A similar protocol was followed in the remaining $12 \mathrm{dogs}$, although they did not receive CPB. Six animals were randomized to receive GSNO (CTRL-GSNO) and 6 were randomized to receive placebo (CTRL-PLAC). All animals received continuous anesthesia and followed a similar protocol to the CPB-treated animals, but they did not have thora- cotomies performed and did not have the aortic, left atrial, and right atrial lines inserted. The drug infusions (GSNO or placebo) were given over times similar to those of the CPBtreated animals. The animals were then observed for a further 4 hours and received infusions of normal saline solution to match the same right atrial $(5-15 \mathrm{~mm} \mathrm{Hg})$ and systemic arterial pressures $(>60 \mathrm{~mm} \mathrm{Hg})$ as the $\mathrm{CPB}$-treated animals. Sodium bicarbonate was infused during $\mathrm{CPB}$ as necessary to maintain arterial $\mathrm{pH}$ between 7.3 and 7.45.

At the conclusion of the studies all 24 animals were killed by a barbiturate overdose. Immediately after death, the heart and lungs were rapidly removed. Biopsy sections $\left(0.5 \mathrm{~cm}^{2}\right)$ from all 4 heart chambers and a 1-cm long portion of the proximal left descending coronary artery were removed, frozen in liquid nitrogen, and preserved for further analysis (see below).

Measurements and calculations. After insertion of all catheters, baseline blood samples were obtained for measurements of hemoglobin, white cell count, and differential. Whole blood samples were also prepared for subsequent analysis of granulocyte CD18 expression by flow cytometry (see below). Arterial and mixed venous blood gases were simultaneously obtained for measurement of blood gases and oxyhemoglobin saturation. Mixed venous and arterial blood gases were directly measured at $37^{\circ} \mathrm{C}$ with appropriately calibrated electrodes (CIBA Corning, model $238 \mathrm{pH}$ Blood Gas Analyzer, Medfield, Mass) and then corrected for core temperature. ${ }^{14}$ Oxyhemoglobin saturation was measured (2500 Co-Oximeter, CIBA Corning), and then intrapulmonary shunt could be calculated. Hemodynamic measurements included cardiac output, systemic arterial pressure, pulmonary artery pressure, pulmonary capillary wedge pressure, left atrial pressure, and right atrial pressure. All measurements were repeated 1 hour and 4 hours after bypass. Measurements of systemic and right atrial pressure were repeated as needed after bypass to maintain our predetermined hemodynamic goals.

Neutrophil expression of CD11b and CD18 was assessed with flow cytometry (FACScan, Becton Dickinson and Company, San Jose, Calif). In brief, $1 \mathrm{~mL}$ of heparinized blood was added to $14 \mathrm{~mL}$ of standard lysing solution $\left(\mathrm{NH}_{4} \mathrm{Cl}\right.$, $\mathrm{KHCO}_{3}$, tetrasodium ethylenediaminetetraacetic acid adjusted to $\mathrm{pH}$ 7.3). Cells were pelleted (1200 rpm for 5 minutes) and resuspended in ice-cold phosphate-buffered saline solution containing $0.1 \%$ bovine serum albumin and $0.01 \%$ sodium azide. Cell labeling procedures were conducted with this same solution, and cells were maintained at $4{ }^{\circ} \mathrm{C}$ throughout the procedure. Cells were reacted with either an irrelevant, isotypematched fluorescein isothiocyanate-conjugated rat monoclonal antibody (MCA1125F) (Serotech Ltd, Oxford, United Kingdom) or fluorescein isothiocyanate-conjugated rat antihuman CD18 (MCA503F; Serotech) that cross-reacted with canine CD18. Cells were then washed 3 times and fixed in $2 \%$ paraformaldehyde. Flow cytometric analyses were performed 24 to 48 hours after cells were labeled, and the analysis was restricted to neutrophils on the basis of forward-angle light scatter and right-angle light scatter. The mean fluorescent intensity of CD18 labeling was used as a measure of CD18 expression. 
Table I. Selected hemodynamic values in all 4 groups

\begin{tabular}{|c|c|c|c|}
\hline $\begin{array}{l}\text { Hemodynamic } \\
\text { value }\end{array}$ & Baseline & $\begin{array}{l}\text { One hour } \\
\text { after bypass }\end{array}$ & $\begin{array}{l}\text { Four hours } \\
\text { after bypass }\end{array}$ \\
\hline \multicolumn{4}{|c|}{ Heart rate (beats/min) } \\
\hline CTRL-PLAC & $100 \pm 36$ & $77 \pm 28$ & $82 \pm 30$ \\
\hline CTRL-GSNO & $124 \pm 30$ & $101 \pm 40$ & $92 \pm 52$ \\
\hline CPB-PLAC & $125 \pm 29$ & $130 \pm 34$ & $156 \pm 16$ \\
\hline CPB-GSNO & $140 \pm 29$ & $146 \pm 18$ & $150 \pm 14$ \\
\hline \multicolumn{4}{|l|}{$\mathrm{P}_{\mathrm{SA}}(\mathrm{mm} \mathrm{Hg})$} \\
\hline CTRL-PLAC & $119 \pm 20$ & $111 \pm 13$ & $110 \pm 15$ \\
\hline CTRL-GSNO & $110 \pm 9$ & $105 \pm 13$ & $100 \pm 17$ \\
\hline CPB-PLAC & $138 \pm 24$ & $87 \pm 15^{*}$ & $87 \pm 22 *$ \\
\hline CPB-GSNO & $106 \pm 23$ & $93 \pm 15^{*}$ & $87 \pm 18^{*}$ \\
\hline \multicolumn{4}{|l|}{$\mathrm{P}_{\mathrm{RA}}(\mathrm{mm} \mathrm{Hg})$} \\
\hline CTRL-PLAC & $5 \pm 2$ & $6 \pm 1$ & $6 \pm 3$ \\
\hline CTRL-GSNO & $5 \pm 2$ & $6 \pm 3$ & $6 \pm 3$ \\
\hline CPB-PLAC & $5 \pm 2$ & $7 \pm 3$ & $6 \pm 3$ \\
\hline CPB-GSNO & $6 \pm 2$ & $6 \pm 2$ & $5 \pm 2$ \\
\hline \multicolumn{4}{|l|}{$\mathrm{P}_{\mathrm{CWP}}(\mathrm{mm} \mathrm{Hg})$} \\
\hline CTRL-PLAC & $9 \pm 2$ & $8 \pm 2$ & $8 \pm 2$ \\
\hline CTRL-GSNO & $8 \pm 2$ & $8 \pm 4$ & $8 \pm 3$ \\
\hline CPB-PLAC & $9 \pm 3$ & $9 \pm 3$ & $10 \pm 4$ \\
\hline CPB-GSNO & $8 \pm 3$ & $8 \pm 2$ & $6 \pm 2$ \\
\hline \multicolumn{4}{|l|}{ SVR (dyne/s/cm $\left.{ }^{5}\right)$} \\
\hline CTRL-PLAC & $7708 \pm 2306$ & $8067 \pm 1789$ & $7731 \pm 2451$ \\
\hline CTRL-GSNO & $6373 \pm 1232$ & $6654 \pm 1885$ & $6331 \pm 1214$ \\
\hline CPB-PLAC & $7787 \pm 1890$ & $7149 \pm 2522$ & $9522 \pm 3309^{*}$ \\
\hline CPB-GSNO & $5738 \pm 2337$ & $5507 \pm 1822$ & $9066 \pm 2712 *$ \\
\hline \multicolumn{4}{|l|}{ PVR (dyne/s/cm5 $)$} \\
\hline CTRL-PLAC & $422 \pm 181$ & $415 \pm 178$ & $480 \pm 241$ \\
\hline CTRL-GSNO & $472 \pm 204$ & $433 \pm 179$ & $437 \pm 150$ \\
\hline CPB-PLAC & $454 \pm 274$ & $753 \pm 256$ & $963 \pm 311$ \\
\hline CPB-GSNO & $457 \pm 191^{*}$ & $517 \pm 251$ & $1156 \pm 476$ \\
\hline \multicolumn{4}{|c|}{ Cardiac output (L/min) } \\
\hline CTRL-PLAC & $1.2 \pm 0.2$ & $1.3 \pm 0.3$ & $1.2 \pm 0.3$ \\
\hline CTRL-GSNO & $1.4 \pm 0.4$ & $1.3 \pm 0.6$ & $1.3 \pm 0.5$ \\
\hline CPB-PLAC & $1.4 \pm 0.2$ & $1.0 \pm 0.4$ & $0.7 \pm 0.2^{*}$ \\
\hline CPB-GSNO & $1.7 \pm 0.9$ & $1.5 \pm 0.8$ & $0.8 \pm 0.2 *$ \\
\hline
\end{tabular}

$\overline{P S A}$, Mean systemic blood pressure; $P R A$, mean right atrial pressure; $P C W P$, pulmonary capillary wedge pressure; $S V R$, systemic vascular resistance (calculated as SVR $=$ PSA - PRA/Cardiac output $\cdot 80) ; P V R$, pulmonary vascular resistance.

*Denotes a significant difference $(P<.05)$ compared with other periods within the same group.

For the measurement of NOS activity, tissue samples were homogenized in a homogenization buffer (tromethamine 50 $\mathrm{mmol} / \mathrm{L}$, sucrose $320 \mathrm{mmol} / \mathrm{L}$, dithiothreitol $1 \mathrm{mmol} / \mathrm{L}$, leupeptin $10 \mu \mathrm{g} / \mathrm{mL}$, soybean trypsin inhibitor $10 \mu \mathrm{g} / \mathrm{mL}$, and aprotinin $2 \mu \mathrm{g} / \mathrm{mL}$ ) by sonication and centrifuged $(10,000 \mathrm{~g}$, 20 minutes, $\left.4^{\circ} \mathrm{C}\right)$. The resultant supernatant was assayed for NOS activity as described. ${ }^{15}$ In brief, tissue aliquots were incubated with $\mathrm{L}\left[\mathrm{U}-{ }^{14} \mathrm{C}\right]$-arginine (Nycomed Amersham, Buckinghamshire, United Kingdom) for 20 minutes at $37^{\circ} \mathrm{C}$ in a potassium phosphate buffer containing the following: reduced nicotinamide adenine dinucleotide, $0.1 \mathrm{mmol} / \mathrm{L}$; tetrahydrobiopterin, $0.01 \mathrm{mmol} / \mathrm{L} ; \mathrm{MgCl}_{2}, 1 \mathrm{mmol} / \mathrm{L} ; \mathrm{CaCL}_{2}$, $0.24 \mathrm{mmol} / \mathrm{L}$; and L-arginine, $20 \mu \mathrm{mol} / \mathrm{L}$. $N^{\mathrm{G}}$-monomethyl-L-
Table II. Selected biochemical and hematologic values in all 4 groups

\begin{tabular}{llcc}
\hline $\begin{array}{l}\text { Biochemical and } \\
\text { hematologic values }\end{array}$ & Baseline & $\begin{array}{c}\text { One hour } \\
\text { after bypass }\end{array}$ & $\begin{array}{c}\text { Four hours } \\
\text { after bypass }\end{array}$ \\
\hline Hemoglobin (g/dL) & & & \\
CTRL-PLAC & $13.5 \pm 1.6^{*}$ & $12.5 \pm 1.7$ & $12.3 \pm 1.8$ \\
CTRL-GSNO & $12.2 \pm 1.5^{*}$ & $11.3 \pm 1.1$ & $11.2 \pm 1.2$ \\
CPB-PLAC & $12.4 \pm 1.8^{*}$ & $7.2 \pm 1.0$ & $6.9 \pm 0.9$ \\
CPB-GSNO & $12.8 \pm 0.8^{*}$ & $7.3 \pm 0.7$ & $7.7 \pm 1.0$ \\
WBC count $\left(10^{9}\right.$ cells) & & & \\
CTRL-PLAC & $8.1 \pm 2.0$ & $7.2 \pm 1.2$ & $7.7 \pm 0.8$ \\
CTRL-GSNO & $6.6 \pm 2.3^{*}$ & $7.7 \pm 2.6$ & $8.6 \pm 2.2$ \\
CPB-PLAC & $5.3 \pm 1.5$ & $5.3 \pm 1.7$ & $6.9 \pm 2.7^{*}$ \\
CPB-GSNO & $6.0 \pm 1.4$ & $5.4 \pm 1.7$ & $6.7 \pm 1.7^{*}$ \\
PO ${ }_{2}$ (mm Hg) & & & \\
CTRL-PLAC & $617 \pm 24$ & $599 \pm 48$ & $626 \pm 18$ \\
CTRL-GSNO & $634 \pm 41$ & $619 \pm 31$ & $615 \pm 90$ \\
CPB-PLAC & $483 \pm 72$ & $285 \pm 197$ & $294 \pm 217$ \\
CPB-GSNO & $456 \pm 109$ & $414 \pm 118$ & $483 \pm 145$ \\
PCO (mm Hg) & & & \\
CTRL-PLAC & $32 \pm 6$ & $34 \pm 7$ & $39 \pm 6^{*}$ \\
CTRL-GSNO & $36 \pm 12^{*}$ & $39 \pm 15$ & $41 \pm 13$ \\
CPB-PLAC & $33 \pm 10$ & $29 \pm 8$ & $31 \pm 10$ \\
CPB-GSNO & $30 \pm 11$ & $35 \pm 12$ & $34 \pm 10$ \\
pH & & & \\
CTRL-PLAC & $7.44 \pm 0.07$ & $7.43 \pm 0.06$ & $7.41 \pm 0.05$ \\
CTRL-GSNO & $7.39 \pm 0.10$ & $7.39 \pm 0.10$ & $7.37 \pm 0.10$ \\
CPB-PLAC & $7.46 \pm 0.08$ & $7.43 \pm 0.09$ & $7.43 \pm 0.09$ \\
CPB-GSNO & $7.38 \pm 0.08$ & $7.43 \pm 0.10$ & $7.43 \pm 0.09$ \\
CD18 expression (units) & & & \\
CTRL-PLAC & $30.3 \pm 8.0$ & $31.0 \pm 10.8$ & $33.6 \pm 9.6$ \\
CTRL-GSNO & $35.9 \pm 14.2$ & $39.2 \pm 16.3$ & $39.8 \pm 15.1$ \\
CPB-PLAC & $27.0 \pm 8.1$ & $27.5 \pm 6.0$ & $35.7 \pm 9.3^{*}$ \\
CPB-GSNO & $25.6 \pm 9.5$ & $28.7 \pm 10.0$ & $26.8 \pm 11.5$ \\
\hline
\end{tabular}

WBC, White blood cell corrected for hemodilution effect; CD18 expression, mean fluorescent intensity of neutrophils for CD18 (see text).

*Denotes a significant difference $(P<.05)$ compared with other periods within same group.

arginine $(1 \mathrm{mmol} / \mathrm{L})$, an inhibitor of NOS, was used to determine NOS-dependent L-citrulline formation as an index of enzyme activity. A $\mathrm{Ca}^{2+}$-chelating agent (ethyleneguanosinetetraacetic acid, $1 \mathrm{mmol} / \mathrm{L}$ ) was used to differentiate between $\mathrm{Ca}^{2+}$-dependent and -independent NOS activities of enzymes that were expressed as picomoles per minute per milligram of protein.

Statistics. Data were compared between period and groups with a 1-way or 2-way analysis of variance as appropriate, and when the $\mathrm{F}$ statistic showed a significant difference, a Student-Newman-Keuls multiple comparison test was used to determine specific group and period differences (SigmaStat, Jandel Scientific, Corte Madera, Calif). We prospectively decided to limit the number of comparisons and we a priori selected to compare only within-group changes over time and to compare only changes between CPB-PLAC with CPBGSNO groups and between CTRL-PLAC with CTRL-GSNO groups. All values are shown as means \pm SD. 


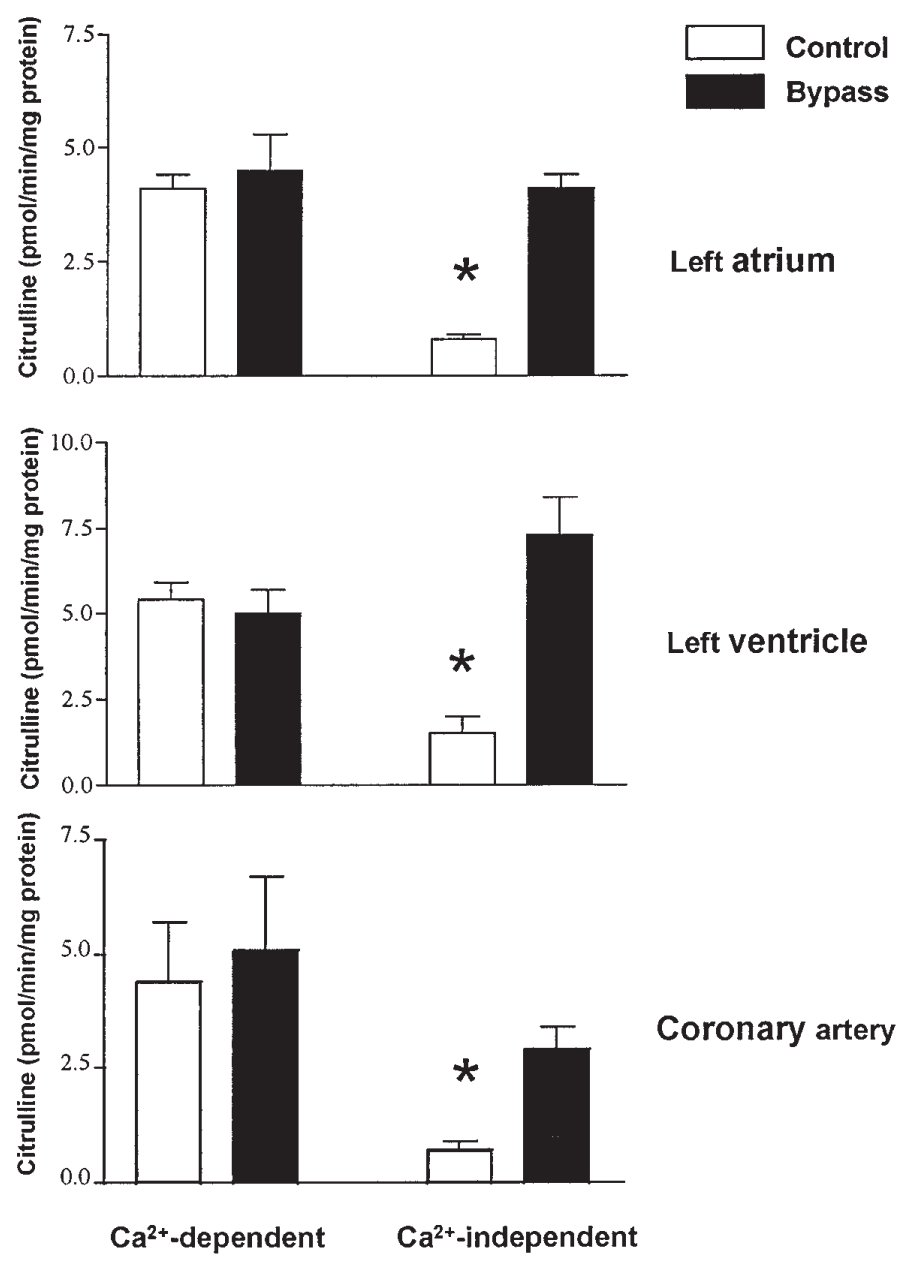

Fig 2. Mean $\pm \mathrm{SD}$ values of $\mathrm{Ca}^{2+}$-dependent and $\mathrm{Ca}^{2+}$-independent NOS activity in placebo-treated animals. Values are shown for left atrium (top), left ventricle (middle), and coronary artery (bottom). Asterisk $(*)$ represents a significant difference $(P<.05)$ between bypass (black bars) and control (white bars) groups. Note that $\mathrm{Ca}^{2+}$-independent NOS activity is markedly increased in the bypass group.

\section{Results}

Hemodynamics. Before GSNO infusion, systemic arterial pressure was similar between the CTRL-GSNO and CPB-GSNO groups $(123 \pm 13 \mathrm{~mm} \mathrm{Hg}$ and $119 \pm 19$ $\mathrm{mm} \mathrm{Hg}$, respectively. To achieve a $10 \%$ reduction of systemic arterial pressure, the total dose of GSNO administered over the course of the study was $30 \pm 7.0$ $\mathrm{mg}$ and $34 \pm 8.3 \mathrm{mg}$ for the CTRL-GSNO and CPBGSNO groups, respectively. There were no differences in hemodynamics (Table I) when the bypass-treated groups were compared (CPB-GSNO with the CPBPLAC groups) or when the control groups were compared (CTRL-GSNO with the CTRL-PLAC groups). Values of systemic arterial pressure, systemic vascular resistance, and cardiac output decreased over time in the
2 CPB-treated groups (baseline vs 4 hours after CPB; $P$ $=.03)$. To achieve our predefined hemodynamic end points (systemic arterial pressure $>60 \mathrm{~mm} \mathrm{Hg}$ and right atrial pressure $<15 \mathrm{~mm} \mathrm{Hg}$ ), the total vasoconstrictor infusion rate was kept higher in the CPB-PLAC group than in the CPB-GSNO group $(3.1 \pm 3.1 \mu \mathrm{g} / \mathrm{min}$ vs 0.2 $\pm 0.4 \mu \mathrm{g} / \mathrm{min}$, respectively; $P=.05$ ). More animals in the CPB-PLAC group (4/6) received phenylephrine than in the CPB-GSNO group (2/6). Total fluid administration was similar between the $2 \mathrm{CPB}$-treated groups $(1200 \pm 488 \mathrm{~mL}$ vs $1475 \pm 293 \mathrm{~mL})$.

CD18 expression in neutrophils. Table II shows values of neutrophil cell surface expression of CD18, hemoglobin, white blood cell counts, and arterial blood gases. Significant hemodilution was observed in all 


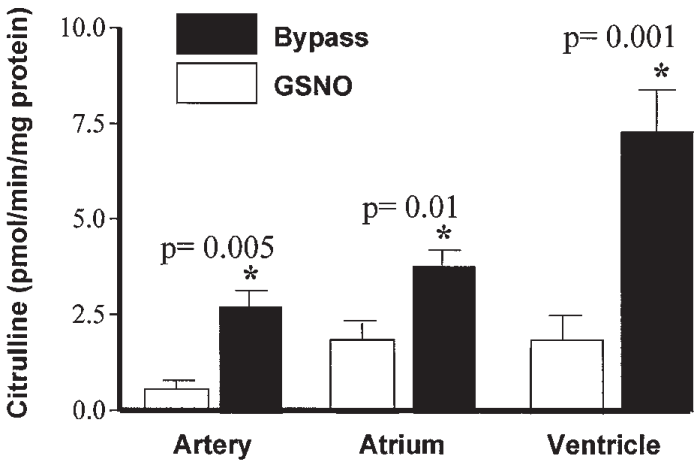

Fig 3. The effects of GSNO administration on $\mathrm{Ca}^{2+}$-independent NOS activity in the left atrium, left ventricle, and coronary artery in bypass-treated animals. The $\mathrm{Ca}^{2+}$-independent NOS activity is represented along the y axis. The solid bars represent animals receiving bypass but treated with placebo. The open bars represent animals receiving bypass and treated with GSNO. Note significant reductions in left atrial, left ventricular, and coronary artery $\mathrm{Ca}^{2+}$-independent $\mathrm{NOS}$ activity in the GSNO-treated animals.

groups throughout the study. After correcting for the degree of hemodilution, the total white blood cell count increased over time in all groups except the CRTLPLAC group. Neutrophils, as a percentage of white blood cells, increased significantly over time in the CPB-PLAC and CPB-GSNO groups from baseline to 4 hours after $\mathrm{CPB}(60 \% \pm 13 \%$ to $77 \% \pm 7 \% ; P=.03$; and $69 \% \pm 6 \%$ to $78 \% \pm 7 \% ; P<.04$, respectively). Concurrently, neutrophil mean fluorescence of CD18 increased from baseline levels to 4 hours after CPB in the CBP-PLAC group $(P=.03)$, whereas values of mean fluorescence did not change significantly in the CPB-GSNO group $(P=.6)$. Similarly, in the 2 groups that did not receive $\mathrm{CPB}$, neutrophil numbers and CD18 expression did not change over time.

Gas exchange. Values of $\mathrm{PO}_{2}$ (Table II) did not change over time in the CTRL-GSNO and in the CTRL-PLAC groups. After CPB, absolute values of $\mathrm{PO}_{2}$ in the CPB-GSNO and CPB-PLAC groups were similar. However, from baseline values to values measured 4 hours after $\mathrm{CPB}, \mathrm{PO}_{2}$ decreased in the CPBPLAC group but increased in the CPB-GSNO group $(-188 \pm 239 \mathrm{~mm} \mathrm{Hg}$ vs $+28 \pm 140 \mathrm{~mm} \mathrm{Hg}$, respectively; $P=.04)$. Intrapulmonary shunt improved over the same time by a mean value of $15.7 \% \pm 14.5 \%$ in the CPB-GSNO group compared with the CPB-PLAC group $(P=.05)$, which did not change over time $(0.0 \%$ $\pm 14.3 \%)$.

NOS activity. Fig 2 illustrates the effects of CPB on $\mathrm{Ca}^{2+}$-dependent and $\mathrm{Ca}^{2+}$-independent NOS activities in the left atrium, ventricle, and coronary artery. The $\mathrm{Ca}^{2+}$-dependent NOS activities were similar between the CTRL-PLAC and the CPB-PLAC groups, but the $\mathrm{Ca}^{2+}$-independent NOS activities were significantly higher $(P=.005)$ in the CPB-PLAC group than in the CTRL-PLAC group. Fig 3 shows the effects of GSNO on the CPB-induced changes in $\mathrm{Ca}^{2+}$-independent NOS activity. The administration of GSNO resulted in levels of $\mathrm{Ca}^{2+}$-independent NOS that were significantly decreased in samples from the ventricle $(P=.001)$, atrium $(P=.01)$, and coronary artery $(P=.005)$ when compared with samples from the CPB-PLAC group. The administration of GSNO to control animals did not influence NOS activity (ie, CRTL-GSNO compared with CTRL-PLAC). The $\mathrm{Ca}^{2+}$-dependent and -independent NOS activities under these conditions were 6.1 \pm 1.5 and $2.3 \pm 1.1 \mathrm{pmol} / \mathrm{min}$ per milligram of protein, respectively, in the CRTL-GSNO group.

\section{Discussion}

Model of CPB. The studies on the cardiovascular effects of CPB are often confounded by the specific surgical procedure used. Indeed, even during sham bypass procedures that include sternotomy and reinfusion of blood collecting in the mediastinum, there is activation of inflammatory pathways. ${ }^{16}$ Therefore, in these experiments, control animals were anesthetized but not subjected to a sham bypass procedure. We have attempted to reproduce human CPB in dogs, but there are some important differences. The dogs, unlike human beings, were not known to have underlying heart disease before CPB. As well, the surgical exposure was obtained via a thoracotomy rather than through a sternal approach. Intraoperatively, bypass grafting was not performed and, finally, an intra-aortic catheter was used to occlude aortic flow instead of an external aortic crossclamp. We also examined whether nonspecific induction of iNOS occurred after thoracotomy in 2 additional control animals, and we did not find evidence of significant iNOS induction. In this study we have not separated the possible role of atrial line insertion on induction of iNOS. Similarly, we have not controlled for the re-infusion of blood that collected within the mediastinum. Rather, these procedures are integral parts of the entire process of CPB. If anything, this study would underestimate the extent of iNOS induction, since we attempted to minimize the surgical trauma associated with the process of CPB.

Bypass-induced activation of NOS. We have measured the activity of NOS in the myocardium and coronary artery and found that $\mathrm{CPB}$ is associated with an increase in the activity of $\mathrm{Ca}^{2+}$-independent NOS. This 
is in agreement with the work by Morita and colleagues, ${ }^{8,17}$ who found that CPB is associated with increased generation of $\mathrm{NO}$ in plasma and myocardium. In the heart, increased activity of $\mathrm{Ca}^{2+}$-independent NOS correlates well with enhanced expression of iNOS. ${ }^{18}$

Increased expression of iNOS with resultant overproduction of NO is often mediated through pro-inflammatory cytokines such as tumor necrosis factor $-\alpha$ or interleukin-1 $\beta$. Cytokines such as interleukin-1 $\beta$, tumor necrosis factor- $\alpha$, and interleukin- 6 are also increased after $\mathrm{CPB},{ }^{6,19}$ and these pro-inflammatory cytokines can also mediate increased NO production in the heart. ${ }^{7}$ It is, therefore, possible that the generation of cytokines mediates the expression of $\mathrm{Ca}^{2+}$-independent NOS and contributes to the clinically observed myocardial dysfunction associated with CPB. ${ }^{20,21}$ However, in our studies we did not measure cytokine production; therefore their possible role remains speculative only. The early myocardial injury may be related in part to increased neutrophil activation and adhesion to the endothelium, reactions involving the generation and release of cytokines. The expression of neutrophil surface adhesion complexes is increased after coronary artery bypass grafting, ${ }^{22}$ and treatment to limit this effect ${ }^{16,23}$ can ameliorate CPB-induced myocardial injury. We hypothesize that the CPBinduced injury is caused by increased neutrophil activation leading to the release of pro-inflammatory cytokines and excessive expression of NO and peroxynitrite $\left(\mathrm{ONOO}^{-}\right)$. Peroxynitrite is a potent tissue-damaging oxidant whose generation often accompanies the expression of iNOS $^{24}$ that can render the coronary circulation nonreactive to vasodilators ${ }^{25}$ and impair myocardial contractility. ${ }^{26}$

NO as a therapeutic target in CPB. If iNOS has a pathogenic role in causing the cellular lesions after $\mathrm{CPB}$, then pharmacologic inhibition of iNOS expression or activity could be clinically beneficial. The results of our study support this hypothesis. We have found that GSNO administration resulted in improved gas exchange, decreased vasopressor requirements, and decreased activation of granulocytes. Moreover, GSNO administration clearly decreased activity of $\mathrm{Ca}^{2+}$-independent NOS. This down-regulation of iNOS expression has been shown in vitro, $, 9,10$ but so far as we are aware, our study is the only in vivo confirmation of these in vitro observations.

We used changes in neutrophil fluorescence-activated cell sorter mean fluorescence for CD18 22 as a surrogate for neutrophil activation and found that GSNO administration limited the increase in leukocyte activa- tion after CPB. NO donors have been shown to inhibit granulocyte activation in vitro ${ }^{27}$ and to inhibit granulocyte-endothelial interactions. ${ }^{28}$ Furthermore, direct administration of $\mathrm{NO}$ gas through the oxygenator in an animal model of CPB can reduce platelet adherence to the membrane, as well as platelet aggregation. ${ }^{29}$ Inhibition of granulocyte activation limits organ injury $^{30}$ and thus any therapeutic effect of GSNO may be at least partially dependent on inhibition of granulocyte CD18 expression or on inhibition of platelet aggregation. However, GSNO may influence other cellular protective effects, and our study was not designed to differentiate between various mechanisms. However, some NO donors do not have similar cytoprotective effects. In an in vitro model, GSNO has been shown to reduce oxidative injury whereas 2 other NO donors, sodium nitroprusside and SIN-1, have been shown to worsen the injury. ${ }^{12}$ Thus our findings with GSNO cannot be extrapolated to all other classes of NO donors.

We have also found that after CPB the placebo-treated animals required more vasoconstrictor than did the GSNO-treated animals to maintain a mean blood pressure of at least $60 \mathrm{~mm} \mathrm{Hg}$. We hypothesize that GSNO reduced expression of inducible NO in the coronary arteries and similarly reduced expression in the systemic vasculature, thus explaining the limited requirement for vasoconstrictor therapy in CPB-GSNO animals. Although the reduction of excessive NO production may have other benefits (eg, reduction of peroxynitrite generation), our study was not designed to answer this question, and any other clinical benefits remain speculative.

In summary, we have shown that CPB causes increased activity of iNOS in the heart, an effect prevented by GSNO. This effect may include the inhibition of granulocyte activation that underlies the CPBinduced injury. Therefore NO donors such as GSNO may represent a new class of compounds that improve clinical outcomes after CPB or other forms of extracorporeal circulation.

We thank M. Pisz for technical assistance and K. Brown for secretarial support.

\section{REFERENCES}

1. Radomski MW. Nitric oxide: biological mediator, modulator and effector. Ann Med 1995;27:321-9.

2. Hare JM, Colluci WS. Role of nitric oxide in the regulation of myocardial function. Prog Cardiovasc Dis 1995;38:155-66.

3. Lefer DJ, Nakanishi K, Johnston WE, Vinten-Johansen J. Antineutrophil and myocardial protecting actions of a novel nitric oxide donor after myocardial ischemia and reperfusion in dogs. Circulation 1993;88:2337-50 
4. Matheis G, Sherman MP, Buckberg GD, Haybron DM, Young $\mathrm{HH}$, Ignarro LJ. Role of L-arginine-nitric oxide pathway in myocardial reoxygenation injury. Am J Physiol 1992;H616-20.

5. Downing SW, Edmunds Jr LH. Release of vasoactive substances during cardiopulmonary bypass. Ann Thorac Surg 1992;54:123643.

6. Kawamura T, Wakusawa R, Okada K, Inada S. Elevation of cytokines during open heart surgery with cardiopulmonary bypass: participation of interleukin 8 and 6 in the reperfusion injury. Can J Anaesth 1993;40:1016-21.

7. Finkel MS, Oddis CV, Jacob TD, Watkins SC, Hattler BG, Simmons RL. Negative inotropic effects of cytokines on the heart mediated by nitric oxide. Science 1992;257:387-9.

8. Morita K, Ihnken K, Buckberg GD, Sherman MP, Young HH, Ignarro LJ. Role of controlled cardiac reoxygenation in reducing nitric oxide production and cardiac oxidant damage in cyanotic infantile hearts. J Clin Invest 1994;93:2658-66.

9. Buga GM, Griscavage JM, Rogers NE, Ignarro LJ. Negative feedback regulation of endothelial cell function by nitric oxide. Circ Res 1993;73:808-12.

10. Assreuy J, Cunha FQ, Liew FY, Moncada S. Feedback inhibition of nitric oxide synthase activity by nitric oxide. Br J Pharmacol 1993;108:833-7.

11. Langford EJ, Brown AS, Wainwright RJ, DeBelder AJ, Thomas MR, Smith REA, et al. Inhibition of platelet activity by Snitrosoglutathione during coronary angioplasty. Lancet 1994; 344:1458-60

12. Wink DA, Cook JA, Pacelli R, DeGraff W, Gamson J, Liebman J, et al. The effect of various nitric oxide-donor agents on hydrogen peroxide-mediated toxicity: a direct correlation between nitric oxide formation and protection. Arch Biochem Biophys 1996;331:241-8.

13. Rees DD, Palmer RMJ, Moncada S. Role of endothelium-derived nitric oxide in the regulation of blood pressure. Proc Natl Acad Sci USA 1989;86:3375-8.

14. Burnett RW, Noonan DC. Calculations and correction factors used in determination of blood $\mathrm{pH}$ and blood gases. Clin Chem 1994;20:1499-506.

15. Radomski MW, Vallance PJ, Whitely G, Foxwell N, Moncada S. Modulation of platelet adhesion to human vascular endothelium by the constitutive and cytokine-inducible nitric oxide syntheses. Cardiovasc Res 1993;27:1380-2.

16. Mayers I, Hurst T, Johnson D, Cujec B, Ang LC, Thomson D, et al. Anti-CD18 antibodies improve cardiac function following cardiopulmonary bypass in dogs. J Crit Care 1996;11:189-97.

17. Morita K, Sherman MP, Buckberg GD, Ihnken K, Matheis G, Young $\mathrm{HH}$, et al. Studies of hypoxemic/reoxygenation injury: without aortic clamping. V. Role of the L-arginine-nitric oxide pathway: the nitric oxide paradox. J Cardiovasc Thorac Surg 1995;110:1200-11.

18. DeBelder A, Radomski MW, Why HJF, Richardson PJ, Bucknall CA, Salas E, et al. Nitric oxide synthase activities in human myocardium. Lancet. 1993;341:84-5.

19. Brasil LA, Gomes WJ, Salomao R, Buffolo E. Inflammatory response after myocardial revascularization with or without cardiopulmonary bypass. Ann Thorac Surg 1998;66:56-9.

20. Gorson J, Diana P, Lee J, Katz WE, Hattler BG. Reversible diastolic dysfunction after successful coronary artery bypass surgery: assessment by transesophageal Doppler echocardiography. Chest 1994;106:1364-9.

21. Breisblatt WM, Stein KL, Wolf CJ, Follansbee WP, Capozzi J, Armitage JM, et al. Acute myocardial dysfunction and recovery: a common occurrence after coronary bypass surgery. J Am Coll Cardiol 1990;15:1261-9.

22. Dreyer WJ, Michael LH, Millman EE, Berens KL. Neutrophil activation and adhesion molecule expression in a canine model of open heart surgery with cardiopulmonary bypass. Cardiovasc Res 1995;29:775-81.

23. Wilson I, Gillinov AM, Curtis WE, DiNatale J, Burch RM, Gardner TJ, et al. Inhibition of neutrophil adherence improves postischemic ventricular performance of the neonatal heart. Circulation. 1993;88(Suppl):II372-9.

24. Darley-Usmar V, Radomski MW. Free radicals in the vasculature: the good, the bad and the ugly. Biochemist 1994;16:15-8.

25. Villa LM, Salas E, Darley-Usmar VM, Radomski MW, Moncada S. Peroxynitrite induces both vasodilatation and impaired vascular relaxation in the rat isolated perfused heart. Proc Natl Acad Sci USA 1994;91:12383-7.

26. Schulz R, Dodge K, Lopaschuk GD, Clanachan S. Peroxynitrite impairs cardiac contractile function by decreasing cardiac efficiency. Am J Physiol 1997;272:H1212-9.

27. Kaplan SS, Billiar T, Curran RD, Zdziarski UE, Simmons RL, Basford RE. Inhibition of chemotaxis with $N^{\mathrm{G}}$-monomethyl-Larginine: a role for cyclic GMP. Blood 1989;74:1885-7.

28. Kubes P, Suzuki M, Grander DN. Nitric oxide: an endogenous modulator of leukocyte adhesion. Proc Natl Acad Sci USA 1991; 88:4651-5.

29. Sly MK, Prager MD, Li J, Harris FB, Shastri P, Bhujle R, et al. Platelet and neutrophil distributions in pump oxygenator circuits. III. Influence of nitric oxide gas infusion. J ASAIO 1996;42: M494-9.

30. Ward PA, Mulligan MS. Role of adherence molecules in lung inflammation. In: Physiology and pathophysiology of leukocyte adhesion. Granger DN, Schmid-Schonbein GW, editors. New York: Oxford University Press. 1995. p. 313-22. 